\title{
Probability analysis of dynamical effects of axial piston hydraulic motor
}

\author{
Alzbeta Sapietova ${ }^{1, *}$, Vladimir Dekys ${ }^{1}$, Milan Sapieta ${ }^{1}$, Peter $_{\text {Sulka }}{ }^{1}$, Lukas Gajdos $^{2}$, \\ Izabela Rojek $^{3}$ \\ ${ }^{1}$ Faculty of Mechanical Engineering, Department of Applied Mechanics, University of Zilina, \\ Univerzitná 1, 01026, Slovakia \\ ${ }^{2}$ Schaeffler Slovakia, Dr. G. Schaefflera 1, 02401 Kysucke Nove Mesto, Slovakia \\ ${ }^{3}$ Kazimierz Wielki University in Bydgoszcz, Institute of Mechanics and Applied Computer Science \\ Bydgoszcz, Kujawsko-Pomorskie, Poland
}

\begin{abstract}
The paper presents an analysis of impact force on stopper screw in axial piston hydraulic motor. The solution contains probabilistic description of input variables. If the output parameters of probabilistic solution are compared with arbitrary values and values acquired by analytical solution, the probability of proper operation of the device can be evaluated.
\end{abstract}

Keywords: probability, dynamic, impact force, MATLAB, hydrostatic motor

\section{Introduction}

We commonly encounter with procedures and approaches in which is physical physic described by a mathematical model. This description requires geomtric parameters, load values and material's variables. The solution is the most often deterministic. In case if we want to consider the variability of the input parameters and realize philosophy of the safety coefficient in the deterministic solution, then the probabilistic approach can be used.

In case of minor variables are the analytical formulas sometimes useful because simulation methods as method Monte Carlo (MMC) are recommended for a larger amount of variables (for example, seven and more). If the correct model is intended and the appropriate solution is applied, it is also necessary to formulate a request for input data in relation to the meaning of object. If are input data in the form of probability density for particular independent variables, the issue is usually simple to sort out. Even though, if these inputs have to been estimated, problems come into being in relation to the production stage, for example: construction tolerances and the distribution of real values within these limits, the stability of the production process and the proceeding in which the production control is carried out. The same problem was solved in [1]. Indefinite input parameters can also be processed, for example, by interval arithmetic or access fuzzy, [2-4].

Equally important is the issue of load, or more precisely its determination, transfer of such data from generic previous devices, the correction of this loading for specific customer

* Corresponding author: alzbeta.sapietova@,fstroj.uniza.sk

Reviewers: Tomasz Domański, Juraj Gerlici 
conditions and similarly. The total allowable time for the solution and the costs of analyse are significant when deciding whether or not to use this method.

\section{Axial piston hydraulic motor}

The magnitude of the dynamic force acting on the stopper bolt was investigated on an axial piston hydraulic cylinder with an inclined block in Figure 1. The pressure is transmitted through the Servo Piston and the Spindle to the Valve Segment. The valve segment, when rotated, comes int contact with the Set Bolt, between which a force is formed. These dynamic effects are further absorbed by the load-bearing structure of the hydromotor. Because in the restraints of servo-binder and in the restraint between the servo-piston and the pin are relatively low friction forces so when considering the maximum pressure achieves a large angular acceleration in the valve segment. This is what they get in hydromotor has significant impact effects that may cause in the contact area creation of small plastic deformations and also in the consequence of cumulation of damage formation lead to the appearing and spreading of crevasses and cracks, [5].

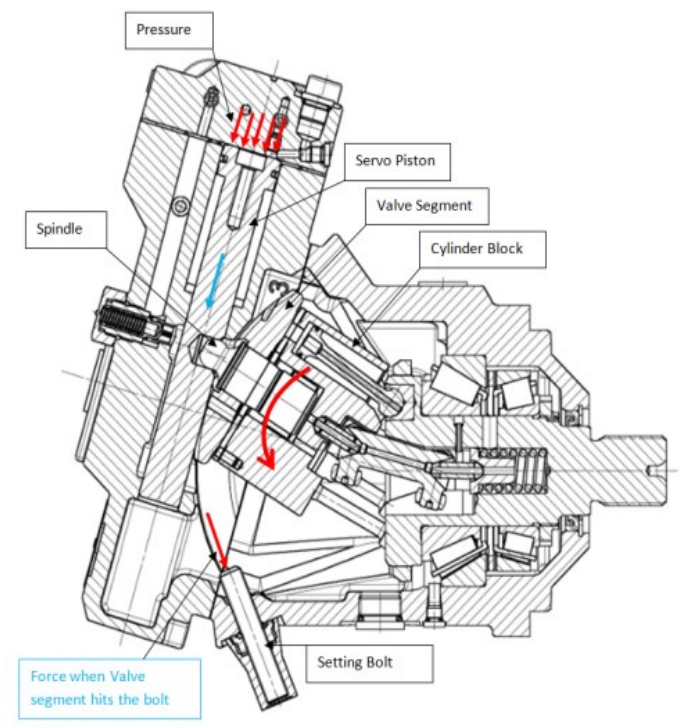

Fig. 1. Hydraulic motor scheme with axial piston with sloping block and labelling effects of load

\section{Calculation of the dynamic force on the stopper crew}

The solution was performed by means of reducing the amount of material and performance. Figure 2 displayed a kinematic diagram of an axial piston hydraulic engine, where: 1 - frame, 2 - servo-piston, 3 - pin, 4 - valve segments, A - impact, v2 - velocity of actuator, $v_{3}$ - velocity between pin and valve, $\omega_{3}-$ angular velocity of the pin, $\omega_{4}-$ angular velocity of the valce segment.

For the resulting force is possible to obtain following equation:

$$
F_{R E D}=\frac{F_{P} r_{B}-I_{R E D} \alpha}{r_{R E D}},
$$

$F_{R E D}$ is the calculated reduced force, $F_{P}$ is the pressure force acting on the servo-piston, $r_{B}$ is the arm on which the force $F_{P}$ acts to the rotating constraint with frame, $I_{R E D}$ is the 
reduced momentum of inertia, $\alpha$ is the angular acceleration, $r_{R E D}$ is the position of the reduced member's center of gravity to the rotating constraint with frame.

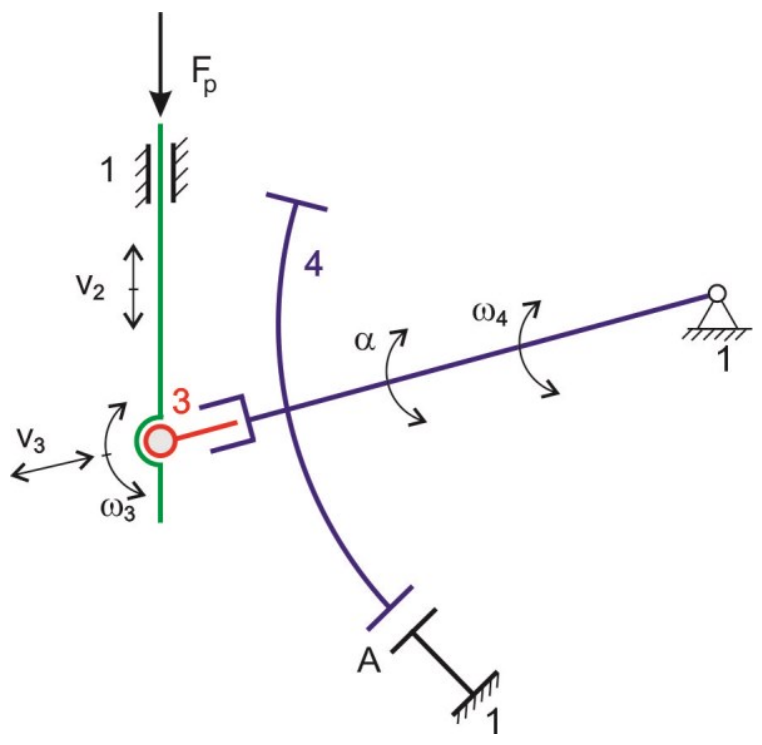

Fig. 2. Kinematic scheme of the axial piston hydraulic motor

The input variables on the right-hand side of the relationship (1) were made in this simplified model by other variables (geometric parameters, values determined on the basis of kinematic and kinetic conditions and material moments of inertia). A total of 9 independent variables, $I n_{k \_ \text {ave }}, k=1, \ldots 9$, were used to calculate the force $F_{R E D}$. One of the input variables was also the angular acceleration of the member 4 of the mechanism of Figure 2. This acceleration was determined by simulation in the MSC.ADAMS program and the average value of this acceleration was estimated based on the average values of the other input variables, [6-8].

\section{Probability analysis of the dynamic force acting on the stop screw}

The basic calculation of the average values of the reduced force $F_{R E D \_a v e}$ was performed for the average values of all input variables $I n_{k \text { ave }}, k=1, \ldots 9$. Subsequently, the task was formulated - to determine the probability $P$ that the random variable $F$ corresponding to the force $F_{R E D}$ will be more than $10 \%$ higher than the value $F_{R E D \_a v e}$ :

$$
P=\operatorname{Prob}\left\{F>1.1 F_{R E D \_a v e}\right\} .
$$

Subsequently, for each input random variable $I_{k}, k=1, \ldots 9$, the estimated interval, variable that is most likely to cover its values. To determine these intervals, an estimate of its average value of $I n_{k}$ ave and the percentile deviation value $\Delta_{k}[\%]$ was used so that:

$$
\operatorname{Prob}\left\{\operatorname{In}_{k} \in\left(\operatorname{In}_{k_{-} a v e}+\delta_{k}, I n_{k_{-} a v e}+\delta_{k}\right)\right\}=\text { most likely, } \delta_{k}=0,01 . \Delta_{k} \cdot \operatorname{In}_{k_{-} a v e} \cdot k=1, \ldots 9 .
$$

From a designer's point of view the estimate of the mean value of the average variable $I n_{k a v e}$ and its possible percentage deviation $\Delta_{\mathrm{k}}$ is comprehensible. In the next step, if we 
want to generate values for input variables from a certain type of probability distribution for the Monte Carlo method, we need to know, for example, in the normal distribution, the mean value of the $\mu_{k}$ and the standard deviation $\sigma_{k}$ for the individual input random variables. This problem can be solved by using estimations $\mu_{k_{-} \text {est }}$ and $\sigma_{k_{-} e s t}$ :

$$
\mu_{k \_s t}=I n_{k \_a v e}, \quad \sigma_{k \_s t}=\delta_{k} / w, k=1, \ldots 9, w=1, \ldots 3 .
$$

There is $w$ a multiple of standard deviation and for example if $w=3$, then:

$$
\operatorname{Prob}\left\{\operatorname{In}_{k} \in\left(\operatorname{In}_{k \_a v e}-\delta_{k}, \operatorname{In}_{k_{-} a v e}+\delta_{k}\right)\right\} \approx 0.997 .
$$

The estimations of probability $P$ by relation (1) was made for 3 cases:

The $1^{\text {st }}$ case, the input random variables were simulated from normal distributions, $N\left(\mu_{k \_s t}, \sigma_{k \_s t}^{2}\right)$. This case corresponds to the state when the $I n_{k}$ values outside the interval are also processed in the simulation, although they should be excluded, i.e.:

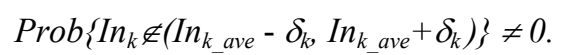

This case corresponds to the non-control of values $I n_{k}$ outside the interval $\left(I n_{k a v e}+\delta_{k}, I n_{k a v e}+\delta_{k}\right)$. The $2^{\text {nd }}$ case, the input random variables were simulated from truncated normal distributions, $N\left(\mu_{k \_s t}, \sigma_{k \_s s t}^{2}\right)$ at interval $\left(\operatorname{In}_{k \_a v e}+\delta_{k}\right.$, $\left.I n_{k \_a v e}+\delta_{k}\right)$. This case corresponds to the state when the $I n_{k}$ values outside the interval are excluded, i.e.:

$$
\operatorname{Prob}\left\{\operatorname{In}_{k} \notin\left(\operatorname{In}_{k_{-} a v e}-\delta_{k}, \operatorname{In}_{k_{-} a v e}+\delta_{k}\right)\right\}=0 .
$$

The exclusion process in $2^{\text {nd }}$ case can be implemented by the production quality control system of the analysed object.

The $3^{\text {rd }}$ case, the input random variables $I n_{k}$ were simulated from uniform distribution at interval $\left(\operatorname{In}_{k \_a v e}-\delta_{k}, I n_{k \_a v e}+\delta_{k}\right)$. This alternative corresponds to relationship (7).

The simulation results are in Table 1.

Table 1. The probability of exceeding an average value of reduced force $F_{d-a v e}$ by at least $10 \%$, point estimate $P$ and interval estimate $\left(P_{\min }, P_{\max }\right)$

\begin{tabular}{|c|c|c|c|c|c|c|c|c|c|}
\hline & & & $1 \%$ & & & & $2 \%$ & & \\
\hline \multirow{2}{*}{ Cause } & $w$ & $\hat{P}_{1}$ & $\hat{p}_{1, \min }$ & $\hat{p}_{1, \max }$ & $r_{1}$ & $\hat{P}_{2}$ & $\hat{p}_{2, \min }$ & $\hat{p}_{2, \max }$ & $r_{2}$ \\
\hline \multirow{3}{*}{1. Normal } & 1 & 0,1619 & 0,1608 & 0,1631 & 8,80 & 0,1689 & 0,1678 & 0,1700 & 4,56 \\
\cline { 2 - 10 } & 2 & 0,0241 & 0,0236 & 0,0246 & 1,31 & 0,0281 & 0,0276 & 0,0286 & 0,76 \\
\cline { 2 - 10 } & 3 & 0,0016 & 0,0014 & 0,0017 & 0,09 & 0,0021 & 0,0020 & 0,0023 & 0,06 \\
\hline \multirow{2}{*}{$\begin{array}{c}2 . \text { Normal } \\
\text { truncated }\end{array}$} & 1 & 0,0129 & 0,0125 & 0,0132 & 0,70 & 0,0269 & 0,0264 & 0,0274 & 0,73 \\
\cline { 2 - 10 } & 2 & 0,0038 & 0,0036 & 0,0040 & 0,21 & 0,0089 & 0,0086 & 0,0091 & 0,24 \\
\hline 3. Uniform & & 0,0004 & 0,0003 & 0,0005 & 0,02 & 0,0011 & 0,0010 & 0,0012 & 0,03 \\
\hline
\end{tabular}

An interpretation of Table 1. A total of 18 simulations were performed, combining the following factors:

- 3 different types of distribution functions of input random variables (normally, normally truncated, uniform) with only one same type of input random variables used in one simulation,

- 3 different values of parameter $w(4)$,

- 2 different input data sets that were characterized by the parameter $\Delta_{k}$ as follows: in both groups, the value for the acceleration parameter was $10 \%$, and the other input parameters were assigned a value of $1 \%$ (in the first group) and $2 \%$ (in the 2 nd group) $3 * 3 * 2=18$. 
For each simulation, probability estimate $\hat{P}_{i}$, interval probability estimate $\left(\hat{p}_{i, \min }, \hat{p}_{i, \max }\right)$ and the ratio between probability for normal, normally truncated and uniform distribution to probability estimate for a uniform distribution, for $i=1.2$ :

$$
\hat{P}_{i}=\frac{n_{i}}{N}
$$

$N$ is the total number of simulations, $N=10^{6}, n_{i}$ is the number of simulations when the $F>1.1 F_{R E D \_a v e}$ condition is satisfied. The interval is defined as:

$$
\left(\hat{p}_{i, \text { min }}, \hat{p}_{i, \max }\right)=\left(\hat{P}_{i}-2 \sqrt{\frac{\hat{P}_{i}\left(1-\hat{P}_{i}\right)}{N}}, \hat{P}_{i}+2 \sqrt{\frac{\hat{P}_{i}\left(1-\hat{P}_{i}\right)}{N}}\right)
$$

The value 2 corresponds to approximately 95\% confidence interval in the relationship (9). In Figure 3, 4 and 5 are the histograms of the simulated $F$ values for $2 \%$ of the input value, Figure 3 for normal distribution ( $w=3$, the cause1), Figure 4 for normal truncated distribution $(w=3$, the cause 1$)$ and Figure 5 for uniform distribution (the cause 1$)$. The histograms for normal and normal truncated (Cause2) distributions are different, for example, the generated values of the force in the normal distribution, case 1 , are in the range approximately $(1300,1900) \mathrm{N}$.

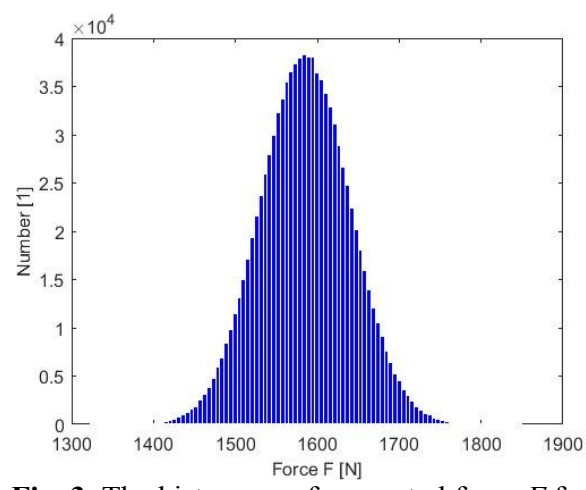

Fig. 3. The histogram of generated force $F$ for normal distribution, the cause 1 .

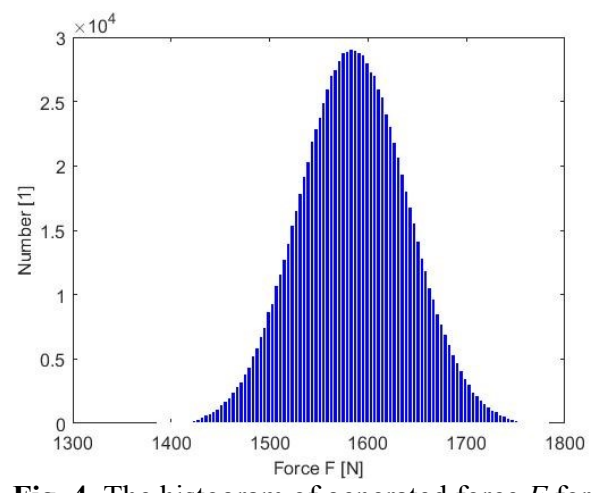

Fig. 4. The histogram of generated force $F$ for normal truncated distribution, the cause 2 .

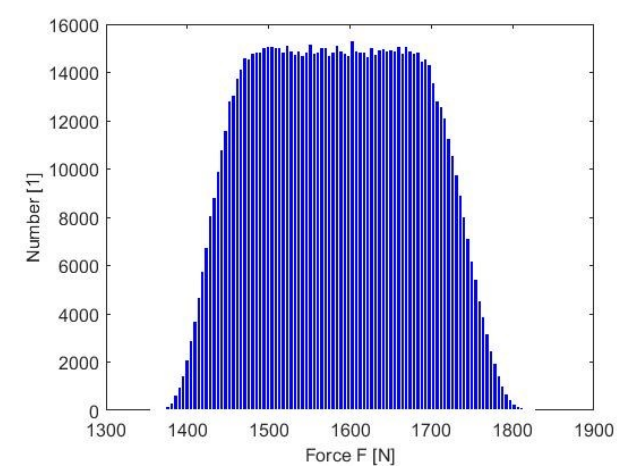

Fig. 5. The histogram of generated force $F$ for uniform distribution, the cause 3. 


\section{Conclusions}

The contribution refers to determining the probability of exceeding the limit value of the selected parameter. For these estimates, the input distribution used plays a significant role. Knowing these distributions may, however, require analysis and regular control of the stability of the production process, which may not be a simple and inexpensive matter [9-15]. If we use the initial estimate to determine the probability of a even distribution of input values, then it is a pessimistic estimate. However, this estimate respects the condition that the input parameter is or is not an element of, for example, tolerance inertial. For example, if we use truncated normal distribution as an estimate, then parameter $w$ should be specified. However, this may imply requirements to increase the cost of a solution if a priori was considered only to discard elements that are characterized by parameters that do not fall within the allowed input value range.

This procedure can also be used to estimate the risk of a fault or a limit state when using safety factors in the design practice.

This work was supported by VEGA 1/0795/16, KEGA 017ŽU-4/2017 and by the Slovak Research and Development Agency under the contract No. APVV-0736-12.

\section{References}

1. A. Sapietová, V. Dekýš, M. Sapieta, P. Pecháč, Application of computational and design approaches to improve carrier stability. Procedia Eng. 96, 410-418 (2014)

2. A. Sapietová, R. Petrech, M. Petrovič, Analysis of the dynamical effects on housing of the axial piston hydromotor. Novel Trends in Production Devices and Systems, Applied Mechanics and Materials 474, 357-362 (2014)

3. M. Kekez, L. Radziszewski, Genetic-fuzzy model of diesel engine working cycle. B POL ACAD SCI-TECH 58, 665-671 (2010)

4. L. Radziszewski, M. Kekez, Application of a genetic-fuzzy system to diesel engine pressure modeling. Int J Adv Manuf Technol. 46, 1-9 (2010)

5. M. Kekez, L. Radziszewski, A Genetic-Fuzzy System for Modelling of Selected Processes in Diesel Engine Fuelled by Biofuels. Biofuel Production - Recent Developments and Prospects, 561-576 (2011)

6. Sapietova, J. Bukovan, M. Sapieta, L. Jakubovicova, Analysis and implementation of input load effects on an air compressor piston in MSC.ADAMS. Book Series: Procedia Engineering 177, 554-561 (2017)

7. A. Sapietová, V. Dekýš, Dynamic analysis of rotating machines in MSC.ADAMS. Procedia Engineering, 136, 143-149 (2016)

8. A. Sapietova, L. Gajdos, V. Dekys, M. Sapieta, Analysis of the Influence of Input Function Contact Parameters of the Impact Force Process in the MSC. ADAMS. Advances in intelligent systems and computing 393, 243-253 (2017)

9. M. Sága, M. Vaško, P. Pecháč, Chosen numerical algorithms for interval finite element analysis. Procedia Engineering 96, 400-409 (2014)

10. M. Handrik, M. Vaško, P. Kopas, V. Mózer, The Linear and Nonlinear Stability Loss of Structures due to Thermal Load. Procedia Engineering 136, 359-364 (2016)

11. M. Sága, P. Kopas, M. Uhríčik, Modeling and experimental analysis of the aluminium alloy fatigue damage in the case of bending - torsion loading. Procedia Engineering 48, 599-606 (2012) 
12. J. Vavro Jr., J. Vavro, P. Kováčiková, R. Bezdedová, Kinematic and dynamic analysis of planar mechanisms by means of the SolidWorks software. Procedia Engineering 177, 476-481 (2017)

13. J. Vavro, J. Vavro Jr., P. Kováčiková, P. Kopas, M. Handrik, Simulation and analysis of defect distribution in passenger car tire under dynamic loading, Applied Mechanics and Materials 611, 544 - 547 (2014)

14. J. Vavro Jr., J. Vavro, P. Kováčiková, P. Kováčiková, R. Bezdedová, J. Híreš, Kinematic and Dynamic Analysis and Distribution of Stress in Items of Planar Mechanisms by Means of the MSC ADAMS Software. Manufacturing Technology 17, 267-270 (2017)

15. P. Pastorek, P. Novak, P. Kopas, Finite element analysis of bond behavior in a steel reinforced concrete structure strengthened carbon fibre reinforced polymer (CFRP) strips. Metalurgija 56, 405-408 (2017) 